\title{
Product Low-Carbon Design using Dynamic Programming Algorithm
}

\author{
Bin $\mathrm{He}^{1, .,}$, Shan Huang', and Jun Wang'
}

1 School of Mechatronic Engineering and Automation, Shanghai Key Laboratory of Intelligent Manufacturing and Robotics, Shanghai University, Shanghai, P.R.China, 200072 \# Corresponding Author / E-mail: mehebin@gmail.com, TEL: +86-21-5633-4383, FAX: +86-21-5633-1775

KEYWORDS: Low-Carbon design, Carbon footprint, Dynamic programming, Product life cycle, Green design

\begin{abstract}
Greenhouse gas emission has become a recent global concern for green manufacturing. As product low-carbon design is an essential approach to achieve low-carbon manufacturing, which has a profound effect on the product carbon footprint, many researches have been focused on it in recent years with a result of valuable contributions. This paper is devoted to presenting a dynamic programmingbased approach to product low-carbon design. After product low-carbon design is characterized by a multi-stage decision process with interaction effects on each other in the product life cycle, a dynamic programming method is used to optimize the total carbon footprint of each stage while considering interaction effects of solutions at each stage in product life cycle. The low-carbon design of a cold heading machine is used to demonstrate the proposed methodology.
\end{abstract}

\section{NOMENCLATURE}

$g_{i}\left(x_{i}, x_{i+1}\right)=$ carbon footprint mapping function of $x_{i}$ and $x_{i+1}$ $f_{k}\left(x_{k}\right)=$ sum of carbon footprint from the $k_{t h}$ to the last stage $s_{i j}=$ design states in set $S_{i}$

$u_{i}\left(x_{i}\right)=$ control variables of $x_{i}$ at the $i_{t h}$ stage

$v_{i}\left(x_{i}, u_{i}\right)=$ carbon footprint under the consideration of $x_{i}$ and $u_{i}$

$x_{i}=$ state variables set in $S_{i}$ at the $i_{t h}$ stage

$x_{i j}=$ state variable set in the design state $s_{i j}$

$x_{i j}{ }^{p}=$ design variables of the $p_{t h}$ solution in $s_{i j}$ at the $i_{t h}$ stage

$C_{i}=$ carbon emission factor of the $i_{t h}$ activity

$D_{i}\left(x_{i}\right)=$ control variables set of $x_{i}$ at the $i_{t h}$ stage

$E_{a}=$ carbon footprint at the acquisition of raw materials stage

$E_{c}=$ carbon footprint in the product life cycle

$E_{i}\left(s_{i k}\right)=$ carbon footprint function of $s_{i k}$ at the $i_{t h}$ stage

$E_{m}=$ carbon footprint at the manufacturing stage

$E_{r}=$ carbon footprint at the recycle and disposal stage

$E_{t}=$ carbon footprint at the transportation stage

$E_{u}=$ carbon footprint at the usage stage

$G_{k}=$ emission of the $k_{t h}$ GHG

$G W P_{k}=$ global warming potential of the $k_{t h} \mathrm{GHG}$

$M_{i}=$ consumption of the $i_{t h}$ activity
$S_{i}=$ design state set at the $i_{t h}$ stage

$T_{k}\left(x_{k}, u_{k}\right)=$ transition function with $k$ stages to go

$U_{k}\left(x_{k}, x_{k+1}\right)=$ control law describing $x_{k}$ and $x_{k+1}$

$X=$ overall state variables of different stages

\section{Introduction}

The emissions of greenhouse gases (GHGs), particularly carbon dioxide, will arouse global climate change. ${ }^{1}$ As a sustainable technology, ${ }^{2}$ the low-carbon technology ${ }^{1}$ is stipulated to industry to reduce GHGs emissions. Derived from ecological footprint, ${ }^{3}$ the product carbon footprint is an indicator on environmental impact for a product. ${ }^{4}$ Generally speaking, product carbon footprint describes the sum of GHGs emissions accumulated during the entire product life cycle. $^{5}$ As a sustainable design, ${ }^{6}$ product low-carbon design has been focused in recent years with a result of many valuable contributions.

The foundation for product low-carbon design is the calculation of product carbon footprint, which is typically estimated by activity data and the corresponding emission factors with life cycle inventory $(\mathrm{LCI})^{4}$-based life cycle assessment (LCA). ${ }^{7}$ He et al. ${ }^{8}$ modeled carbon footprint of design solutions in conceptual design through Unascertained Theory. The essential 
for product low-carbon design is the reduction of GHGs emissions in its life cycle. For instance, Song et al. ${ }^{9}$ proposed low-carbon design system based on the bill of materials (BOM) integrated with GHGs emissions data. Lee et al. ${ }^{10}$ integrated carbon footprint in vendor selection. Su et al. ${ }^{11}$ reduced carbon footprint through optimal structure, assembly sequence, and suppliers as well. Kuo et al. ${ }^{12}$ developed a collaborative design framework to integrate carbon footprint with life cycle inventory database in enterprise resource planning.

Low-carbon design is a design process embedded with GHGs emissions in product life cycle. Its typical results are the design solutions with low GHGs emissions throughout the entire product life cycle. However, the current research efforts always focus on the mapping from the life cycle inventory to carbon footprint through LCA. There are several LCA optimization methods, such as multiobjective optimization, ${ }^{13}$ productive resources maximization, ${ }^{14}$ etc. Since the product life cycle has several stages, the low-carbon design process can be viewed as a multi-stage decision process. The main contribution of this paper is to propose a dynamic programming-based multi-stage decision process of low-carbon design for product life cycle. And in this way, it is obtained with the low-carbon solutions of the lowest carbon footprint in its entire life cycle.

The remainder of this paper is organized as follows. Section 2 described the model of product carbon footprint for product life cycle. In Section 3, after product low-carbon design is characterized by a multi-stage decision process with interaction effects on each other based on the stage of product life cycle, from which product lowcarbon design is transferred to a problem to find the shortest path based on dynamic programming, a dynamic programming method is then used to optimize the total carbon footprint of these stages while considering interaction effects. The low-carbon design of a cold heading machine is used to demonstrate the proposed methodology in Section 4. And Section 5 concludes this paper.

\section{Product Carbon Footprint in Product Life Cycle}

Low-carbon design integrates significant GHGs emissions aspects into product design in its entire life cycle, which consists of five stages, i.e. raw materials acquisition, manufacturing, transportation, usage, and recycle and disposal stage. The typical results of low-carbon design are the generation of products with the reduction of GHGs emissions throughout the life cycle. Since the majority of carbon footprint for a product is determined at its design stage, product low-carbon design is an essential approach to achieve low-carbon manufacturing fundamentally, which has a profound effect on the product carbon footprint. According to the definition of life cycle, the overall product carbon footprint of life cycle is defined as:

$$
E_{c}=E_{a}+E_{m}+E_{t}+E_{u}+E_{r}
$$

where $E_{c}, E_{a}, E_{m}, E_{t}, E_{u}$, and $E_{r}$ is carbon footprint in the product life cycle, at the acquisition of raw materials stage, the manufacturing stage, the transportation stage, the usage stage, and the recycle and disposal stage, respectively.

The calculation models are followed in detail at each stage of the product life cycle.
(1) Carbon footprint at the acquisition of raw materials stage is calculated as

$$
E_{a}=\sum_{i=1}^{n_{1}} \sum_{j=1}^{n_{2}} M_{i j} C_{i j}+\sum_{s=1}^{n_{3}} \sum_{t=1}^{n_{4}} G_{s t} G W P_{t}
$$

where $M_{i j}$ is the consumption of the $j_{t h}$ material for the $i_{t h}$ component, $C_{i j}$ is the emission factor of the $j_{t h}$ material acquired for the $i_{t h}$ component, $G_{s t}$ is the emission of the $t_{t h}$ GHG in the acquisition of the $s_{t h}$ material, GWP $P_{t}$ is the global warming potential of the $t_{t h}$ GHG, $\mathrm{n}_{1} \sim \mathrm{n}_{4}$ is element number.

(2) Carbon footprint at the manufacturing stage is calculated as

$$
E_{m}=\sum_{i=1 j=1}^{n_{1}} \sum_{i j}^{n_{2}} P_{i j} C_{i j}+\sum_{k=1}^{n_{3}} \sum_{l=1}^{n_{4}} A_{k l} C_{k l}+\sum_{m=1}^{n_{5}} \sum_{n=1}^{n_{6}} W_{m n} C_{m n}+\sum_{s=1}^{n_{7}} \sum_{t=1}^{n_{8}} G_{s t} G W P_{t}
$$

where $P_{i j}$ is quantity of the $j_{t h}$ energy consumed in the $i_{t h}$ manufacturing process, $A_{k l}$ is quantity of the $l_{t h}$ energy consumed in the $k_{t h}$ assembly process, $W_{m n}$ is quantity of the $n_{t h}$ waste in the $m_{t h}$ manufacturing/ assembly process, $C_{i j}$ is emission factor of the $j_{t h}$ energy consumed in the $i^{\text {th }}$ manufacturing process, $C_{k l}$ is emission factor of the $l_{t h}$ energy consumed in the $k_{t h}$ assembly process, $C_{m n}$ is emission factor of the $n_{t h}$ waste in the $m_{t h}$ manufacturing/assembly process, $G_{s t}$ is emission of the $t_{t h}$ GHG in the $s_{t h}$ manufacturing/assembly process, $\mathrm{n}_{1} \sim \mathrm{n}_{8}$ is element number.

(3) Carbon footprint at the transportation stage is calculated as

$$
E_{t}=\sum_{i=1}^{n_{1}} \sum_{j=1}^{n_{2}} \sum_{k=1}^{n_{3}} Q_{i j} L_{i j} E I_{i j k} C_{i j k}+\sum_{s=1}^{n_{4}} \sum_{t=1}^{n_{5}} G_{s t} G W P_{t}
$$

where $Q_{i j}$ is quantity of the $j_{t h}$ transportation object (including materials, parts, products and waste) in the $i_{t h}$ transportation mode, $L_{i j}$ is transportation distance of the $j_{t h}$ transportation object in the $i_{t h}$ transportation mode, $E I_{i j k}$ is energy intensity of the $k_{t h}$ energy in transporting the $j_{t h}$ object by the $i_{t h}$ transportation mode, $C_{i j k}$ is emission factor of the $k_{t h}$ energy in transporting the $j_{t h}$ object by the $i_{t h}$ transportation mode, $G_{s t}$ is emission of the $t_{t h}$ GHG by using the $s_{t h}$ energy at the transportation stage, $\mathrm{n}_{1} \sim \mathrm{n}_{5}$ is element number.

(4) Carbon footprint at the usage stage is calculated as

$$
\begin{gathered}
E_{u}=\sum_{i=1}^{n_{1}}\left(\sum_{j=1}^{n_{2}} U_{i j} C_{i j}+\sum_{k=1}^{n_{3}} D_{i k} C_{i k}\right) \\
+\sum_{m=1}^{n_{4}} \sum_{n=1}^{n_{5}}\left(M_{m n} C_{m n}+F_{m n} E F_{m n}\right) \frac{L}{L_{m n}}+\sum_{s=1}^{n_{6}} \sum_{t=1}^{n_{7}} G_{s t} G W P_{t}
\end{gathered}
$$

where $U_{i j}$ is quantity of the $j_{t h}$ energy consumed in the $i_{t h}$ module, $D_{i k}$ is quantity of the $k_{t h}$ energy consumed in monitoring the $i_{t h}$ module in the maintenance process, $M_{m n}$ is quantity of the material consumed in repairing the $n_{t h}$ part of the $m_{t h}$ module, $F_{m n}$ is quantity of the energy consumed in repairing the $n_{t h}$ part of the $m_{t h}$ module, $C_{i j}$ is emission factor of the $j_{t h}$ energy consumed in the $i_{t h}$ module, $C_{i k}$ is emission factor of the $k_{t h}$ energy consumed in monitoring the $i_{t h}$ module in the maintenance process, $C_{m n}$ is emission factor of materials consumed in repairing the $n^{\text {th }}$ part of the $\mathrm{m}_{\mathrm{th}}$ module, $E F_{m n}$ is emission factor of the energy consumed in repairing the $n_{t h}$ part of the $m_{t h}$ module, $L$ is service life of the product, $L_{m n}$ is service life of the $n_{t h}$ part of the $m_{t h}$ module, $G_{s t}$ is emission of the $t_{t h}$ GHG in the $s_{t h}$ module in the usage stage, $\mathrm{n}_{1} \sim \mathrm{n}_{7}$ is element number.

(5) Carbon footprint at the recycle and disposal stage is calculated as 


$$
\begin{gathered}
E_{r}=\sum_{i=1}^{n_{1}}\left(\sum_{j=1}^{n_{2}} D_{i j} C_{i j}+\sum_{k=1}^{n_{3}} W_{i k} C_{i k}\right)+\sum_{m=1}^{n_{4}}\left(\sum_{n=1}^{n_{5}} R_{m n} C_{m n}-G_{m} R A_{m}\right) \\
+\sum_{p=1}^{n_{6}}\left(\sum_{q=1}^{n_{7}} M_{p q} C_{p q}-G_{p} R A_{p}\right)+\sum_{s=1}^{n_{8}} \sum_{t=1}^{n_{9}} G_{s t} G W P_{t}
\end{gathered}
$$

where $D_{i j}$ is quantity of the $j_{t h}$ energy consumed in disassembling the $i_{t h}$ component, $W_{i k}$ is quantity of the $k_{t h}$ energy consumed in the waste disposal of the $i_{t h}$ component, $R_{m n}$ is quantity of the $n_{t h}$ energy consumed in recycling the $m_{t h}$ component, $M_{p q}$ is quantity of the $q_{t h}$ energy consumed in recycling the $p_{t h}$ material, $C_{i j}$ is emission factor of the $j_{t h}$ energy consumed in disassembling the $i_{t h}$ component, $C_{i k}$ is emission factor of the $k_{t h}$ energy consumed in the waste disposal of the $i_{t h}$ component, $C_{m n}$ is emission factor of the $n_{t h}$ energy consumed in recycling the $m_{t h}$ component, $C_{p q}$ is emission factor of the $q_{t h}$ energy consumed in recycling the $p_{t h}$ material, $G_{m}$ is equivalent carbon emission of the $m_{t h}$ part or component, $R A_{m}$ is ratio of the $m_{t h}$ recycling part or component to the original component, $G_{p}$ is equivalent carbon emission of the $p_{t h}$ material, $R A_{p}$ is ratio of the $p_{t h}$ recycling material to the original material, $G_{s t}$ is emission of the $t_{t h}$ GHG in the recycle and disposal of the $s_{t h}$ material, part or component, $\mathrm{n}_{1} \sim \mathrm{n}_{9}$ is element number.

\section{Dynamic Programming-Based Product Low-Carbon Design}

\subsection{Design State in Product Low-Carbon Design at Each Stage of the Product Life Cycle}

There are five stages in the product life cycle. At the $i_{t h}$ stage of product life cycle, there are some choices to be chosen and transferred to the subsequent stage of the product life cycle, denoted as design state set $S_{i}$ with some design states $s_{i j}$.

$$
S_{i}=\left\{s_{i 1}, s_{i 2}, s_{i 3}, \ldots, s_{i j}, \ldots, s_{i m}\right\}
$$

where $s_{i j}(i=0,1,2,3,4,5 ; j=1,2, \ldots, m)$ is a design state in design state set $S_{i}$ at the $i_{t h}$ stage in product life cycle, and $\mathrm{m}$ is the number of choices at the $i_{t h}$ stage in product life cycle.

For instance, at the acquisition of raw materials stage, it has several choices of raw materials to achieve design requirements, which generates design state set at the acquisition of raw materials stage $S_{1}=\left\{s_{11}, s_{12}, \ldots\right.$, $\left.s_{1 j}, \ldots, s_{1 a}\right\}$. All choices of raw materials solutions $s_{1 j}$ in $S_{1}$ might correspond with some manufacturing processes, which generates design state set at the manufacturing stage $S_{2}=\left\{s_{21}, s_{22}, \ldots, s_{2 j}, \ldots, s_{2 m}\right\}$. After manufacturing, there are several transportation ways at the transportation stage corresponding with manufacturing process $s_{2 j}$ in $S_{2}$, which generates design state set at the transportation stage $S_{3}=\left\{s_{31}, s_{32}, \ldots, s_{3 j}\right.$, ..., $\left.s_{3 t}\right\}$. After transportation, it might be used in different ways at the usage stage corresponding with above transportation ways $s_{3 j}$ in $S_{3}$, which generates design state set at usage stage $S_{4}=\left\{s_{41}, s_{42}, \ldots, s_{4 j}, \ldots\right.$, $\left.s_{4 u}\right\}$. After the usage, there are also several solutions to recycle and disposal corresponding with above usage means $s_{4 j}$ in $S_{4}$, which generates design state set at the recycle and disposal stage $S_{5}=\left\{s_{51}, s_{52}, \ldots, s_{5 j}, \ldots\right.$, $\left.s_{5 r}\right\}$. Since $S_{i}$ is defined recursively, it is necessary to put an initiate design state $S_{0}=\left\{s_{01}\right\}$ before the acquisition of raw materials stage and a final design state $S_{6}=\left\{s_{61}\right\}$ after the recycle and disposal stage.

\subsection{State Variables and Control Variables in Product Low- Carbon Design}

The state variable set $x_{i j}$ in the design state $s_{i j}$ at the $\mathrm{i}_{\text {th }}$ stage of product life cycle is defined as:

$$
x_{i j}=\left\{x_{i j}^{1}, x_{i j}^{2}, x_{i j}^{3}, \ldots, x_{i j}^{p}, \ldots, x_{i j}^{m}\right\}
$$

where $x_{i j}^{p}$ is defined as design variables of the $p_{t h}$ solution in design state $s_{i j}$ at the $i_{t h}$ stage of product life cycle, $\mathrm{m}$ is the number of state variables in the current alterative solution.

The state variables set $x_{i}$ in the design state set $S_{i}$ at the $i_{t h}$ stage of product life cycle is then defined as:

$$
x_{i}=\left\{x_{i 1}, x_{i 2}, \ldots, x_{i j}, \ldots, x_{i k}\right\}
$$

where $k$ is the number of state variables in all the solutions at the $i_{t h}$ stage of product life cycle.

Thus, overall state variables $X$ of different stages is as follows:

$$
X=\left\{x_{1}, x_{2}, x_{3}, x_{4}, x_{5}, x_{6}\right\}
$$

The control variables $u_{i}\left(x_{i}\right)$ at the $i_{t h}$ stage of product life cycle are calculated based on the state variables set $x_{i}$ at the $i_{t h}$ stage and the corresponding state variables set $x_{i+1}$ at the next stage of product life cycle, as follows:

$$
u_{i} \in D_{i}\left(x_{i}\right)=g_{i}\left(x_{i}, x_{i+1}\right)
$$

where $u_{i}\left(x_{i}\right)$ is the control variables of the state variables set $x_{i}$ at the $i_{t h}$ stage of product life cycle, $D_{i}\left(x_{i}\right)$ is control variables set of the state variables set $x_{i}$ at the $i_{t h}$ stage of product life cycle, and $g_{i}\left(x_{i}\right.$, $x_{i+1}$ ) is carbon footprint mapping function of the state variables set $\mathrm{x}_{\mathrm{i}}$ of this stage and the corresponding state variables set $x_{i+1}$ in the next stage.

\subsection{Objective Function Calculating Approaches based on the Total Product Carbon Footprint}

The product carbon footprint is shown as follows:

$$
v_{i}\left(x_{i}, u_{i}\right)=E_{i}\left(s_{i k}\right)
$$

where $v_{i}\left(x_{i}, u_{i}\right)$ is the step carbon footprint of at the $i_{t h}$ stage under the consideration of state variables set $x_{i}$ and control variables $u_{i}$, and $E_{i}\left(s_{i k}\right)$ is the function of carbon footprint of design state $s_{i k}$ at the $i_{t h}$ stage. The product carbon footprint of each stage can be calculated with the equations from Eq. (2) to Eq. (6).

The total objective function $M$ is the sum of carbon footprints in above six stages, i.e. Stage 0: Initial stage, Stage 1: Acquisition of raw materials stage, Stage 2: Manufacturing stage, Stage 3: Transportation stage, Stage 4: Usage stage, and Stage 5: Recycle and disposal stage.

$$
M=\min \sum_{k=0}^{5} v_{k}\left(x_{k}, u_{k}\right)
$$

The cost-to-go function $f_{k}\left(x_{k}\right)$ of the $k_{t h}$ stage is the sum of carbon footprint from this stage to the last stage. Since the search of the least optimal carbon 
footprint at each stage is independent of the initial stages and controls used before the current stage, the goal, to seek the minimum of the cost-to-go function of the current stage, is only related to the stage carbon footprint of the current stage and the cost-to-go function of the previous stage, as follows:

$$
f_{k}\left(x_{k}\right)=\min _{u_{k} \in D_{k}\left(x_{k}\right)}\left(v_{k}\left(x_{k}, u_{k}\right)+f_{k-1}\left(x_{k-1}\right)\right)
$$

where $D_{k}\left(x_{k}\right)$ is the control variable set of permissible decisions.

\subsection{Dynamic Programming-Based Product Low-Carbon Design Model}

The dynamic programming method is applicable to the multi-stage decision process in product low-carbon design as shown in Fig. 1, in which each stage of the product life cycle might be seen as a decision stage. The product low-carbon design decision stages of dynamic programming model are linked to the above stages in product life cycle. It must be mentioned that there may be some choices without further considerations in the next stage for some reasons, named as invalid choices. For instance, the current solution can not be supported by the subsequent stage, such as with the initial choice of a certain new material, whose manufacturing process is difficult and then given up in the following process. These types of design states, such as $s_{12}, s_{2 p}$, and $s_{3 i}$ shown in Fig. 1 are marked with dashed lines.

The design variables of different stage are used as the state variables. The control law of dynamic programming model used here is to determine the solution of the next stage based on the current stage. The control variable of each decision stage is a next stage's state variable, and therefore the domain of definition of the control variable, and therefore the domain of definition of the control variable of each decision stage is a next stage's state variable, and therefore the domain of definition of the control variable consists of the available values of the choice of the next stage. Moreover, the carbon footprint of each stage is used as the step carbon footprint of each decision stage.

The least carbon footprint decisions for different steps are to be found one stage after another stage, which are well adapted to apply the Bellman's Principle of Optimality, ${ }^{15}$ which states that an optimal policy has the property that whatever the initial state and initial decision are, the remaining decisions must constitute an optimal policy with regard to the state resulting from the first decision. The optimal product low-carbon design model of dynamic programming problem can be formulated as follows:
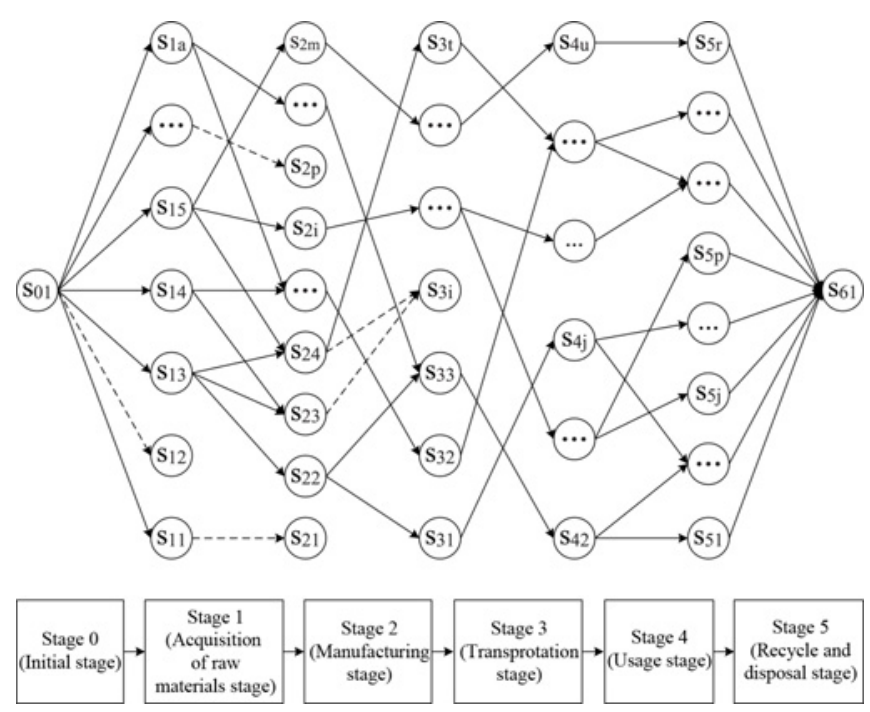

Fig. 1 Dynamic programming-based product low-carbon design

$$
\begin{gathered}
v_{k}\left(x_{k}, u_{k}\right)=\min \left\{f_{k}\left(x_{k}, u_{k}\right)+v_{k-1}\left[T_{k}\left(x_{k}, u_{k}\right)\right]\right\} \\
\text { subject to: } x_{k} \in X_{k}\left(x_{k}\right) ; u_{k}=U_{k}\left(x_{k}, x_{k+1}\right) \in D_{k}\left(u_{k}\right)
\end{gathered}
$$

where $N$ is the total number of decision stages; $k$ is the node number; $v_{k}\left(x_{k}, u_{k}\right)$ is carbon footprint of the $k_{t h}$ stage; $x_{k}$ is state variable set; $X_{k}$ is state variable set of permissible decisions; $u_{k}$ is the control variable; $D_{k}\left(u_{k}\right)$ is the control variable set of permissible decisions; $T_{k}\left(x_{k}, u_{k}\right)$ is the transition function with $\mathrm{k}$ stages to go, which is an implicit function deciding the previous stage's stage varibles $x_{k-1}$ based on the current stage' stage variables $x_{k}$ and control variables $u_{k} ; U_{k}\left(x_{k}, x_{k+1}\right)$ is the control law describing the control variables' dependent relationship on the state variables of the considered stage and the previous stage. The backward optimal path is decided based on the mapping relationship $T_{k}$ connecting stages and the control law $U_{k}$.

Since $v_{k}\left(x_{k}, u_{k}\right)$ is defined recursively in terms of $\mathrm{v}_{k 1}\left(x_{k-1}, u_{k-1}\right)$, in order to solve Eq. (15), it is necessary to initiate the computation by solving the stage-zero problem. ${ }^{16}$ The stage-zero problem is not defined recursively, since there are no more stages before the initial stage of the decision process. To simplify the expression, a dummy carbon footprint is added for the first stage, and the stage-zero problem is then the following:

$$
v_{0}\left(x_{0}, u_{0}\right)=0
$$

\subsection{Dynamic Programming Algorithm-Based Product Low- Carbon Design}

The dynamic programming algorithm-based product low-carbon design is given as follows. At first, those invalid choices at each stage in product life cycle are deleted from the product low-carbon design model. Starting from the last $(\mathrm{N}-1)_{\text {th }}$ stage, one determines the optimal carbon footprint for each state variable at the $(\mathrm{N}-2)_{\text {th }}$ stage based on all the available control variables. Then, knowing the optimal carbon footprint of each state variable at the $(\mathrm{N}-2)_{\text {th }}$ stage, one determines the optimal carbon footprint for each state variable at the $(\mathrm{N}-3)_{\text {th }}$ stage, again using all the available control variables. This procedure continues recursively backward until the Stage 0 , from which the optimal carbon footprint to the entire dynamic programming problem is finally obtained.

According to the dynamic programming model, the total number of decision stage $N=6$, the optimization process starts at $k=5$, and continues recursively down to $k=0$ using Eq. (15), and then the optimal total objective function, i.e. the least carbon footprint in the product cycle can be obtained.

\section{Application}

\subsection{Problem Configuration}

As a case study, a cold heading machine is given as an example of lowcarbon design for the product life cycle, and the result is analysed to verify the feasibility of the proposed low-carbon design model. It is an important performance for low-carbon of cold heading machine. There are choices at each stage of product life cycle proposed in detail in reference. ${ }^{17}$

\subsection{State Variables and Control Variables}

There are many choices at each stage of product life cycle. Therefore the state variables set of each decision stage, i.e. the values of the state variables, can be given by: 


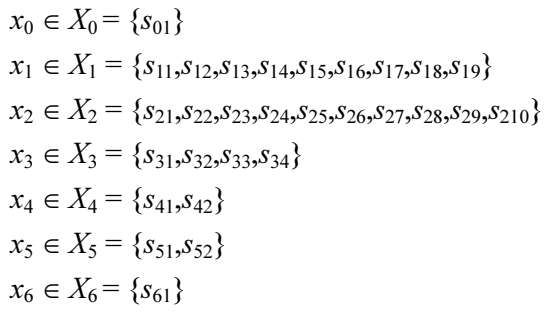

As there are some invalid design states, such as $s_{16}, s_{23}$ and $s_{27}$, after ignoring these invalid design states, the feasible values of the state variables are simplified as:

$$
\begin{aligned}
& x_{0} \in X_{0}=\left\{s_{01}\right\} \\
& x_{1} \in X_{1}=\left\{s_{11}, s_{12}, s_{13}, s_{14}, s_{15}, s_{17}, s_{18}, s_{19}\right\} \\
& x_{2} \in X_{2}=\left\{s_{21}, s_{22}, s_{24}, s_{25}, s_{26}, s_{28}, s_{29}, s_{210}\right\} \\
& x_{3} \in X_{3}=\left\{s_{31}, s_{32}, s_{33}, s_{34}\right\} \\
& x_{4} \in X_{4}=\left\{s_{41}, s_{42}\right\} \\
& x_{5} \in X_{5}=\left\{s_{51}, s_{52}\right\} \\
& x_{6} \in X_{6}=\left\{s_{61}\right\}
\end{aligned}
$$

According to the calculating approaches presented in Section 3, the step carbon footprint related to all possible control laws in each decision stage is listed as the control variables at each decision stage, i.e. the available values of control variables, are as follows:

$$
\begin{aligned}
& D_{0}\left(s_{01}\right)=x_{1} ; \\
& D_{1}\left(s_{11}\right)=\left\{s_{21}, s_{22}\right\} \subseteq x_{2}, D_{1}\left(s_{12}\right)=\left\{s_{24}, s_{29}\right\} \subseteq \mathrm{x}_{2}, D_{1}\left(s_{13}\right)=\left\{s_{23}, s_{27}\right\} \subseteq x_{2}, \\
& D_{1}\left(s_{14}\right)=\left\{s_{21}, s_{22}\right\} \subseteq x_{2}, D_{1}\left(s_{15}\right)=\left\{s_{21}, s_{22}, s_{26}\right\} \subseteq x_{2}, \\
& D_{1}\left(s_{17}\right)=\left\{s_{25}, s_{26}, s_{28}\right\} \subseteq x_{2}, D_{1}\left(s_{18}\right)=\left\{s_{210}\right\} \subseteq \mathrm{x}_{2}, D_{1}\left(s_{19}\right)=\left\{s_{24}, s_{29}\right\} \subseteq x_{2} ; \\
& D_{2}\left(s_{21}\right)=\left\{s_{31}, s_{32}\right\} \subseteq x_{3}, D_{2}\left(\mathrm{~s}_{22}\right)=\left\{s_{34}\right\} \subseteq \mathrm{x}_{3}, \mathrm{D}_{2}\left(s_{24}\right)=\left\{s_{31}, s_{33}\right\} \subseteq x_{3}, \\
& D_{2}\left(s_{25}\right)=\left\{s_{31}, s_{32}\right\} \subseteq x_{3}, D_{2}\left(\mathrm{~s}_{26}\right)=\left\{s_{31}, s_{32}\right\} \subseteq x_{3}, \\
& D_{2}\left(s_{28}\right)=\left\{s_{34}\right\} \subseteq \mathrm{x}_{3}, D_{2}\left(\mathrm{~s}_{29}\right)=\left\{s_{31}, s_{33}\right\} \subseteq x_{3}, D_{2}\left(s_{210}\right)=\left\{s_{31}, s_{32}\right\} \subseteq x_{3} ; \\
& D_{3}\left(s_{31}\right)=D_{3}\left(\mathrm{~s}_{32}\right)=D_{3}\left(\mathrm{~s}_{33}\right)=D_{3}\left(s_{34}\right)=x_{4} ; \\
& D_{4}\left(s_{41}\right)=D_{4}\left(\mathrm{~s}_{42}\right)=x_{5} ; \\
& D_{5}\left(s_{51}\right)=D_{5}\left(\mathrm{~s}_{52}\right)=x_{6} .
\end{aligned}
$$

The state variables set and control variables set are explicitly shown

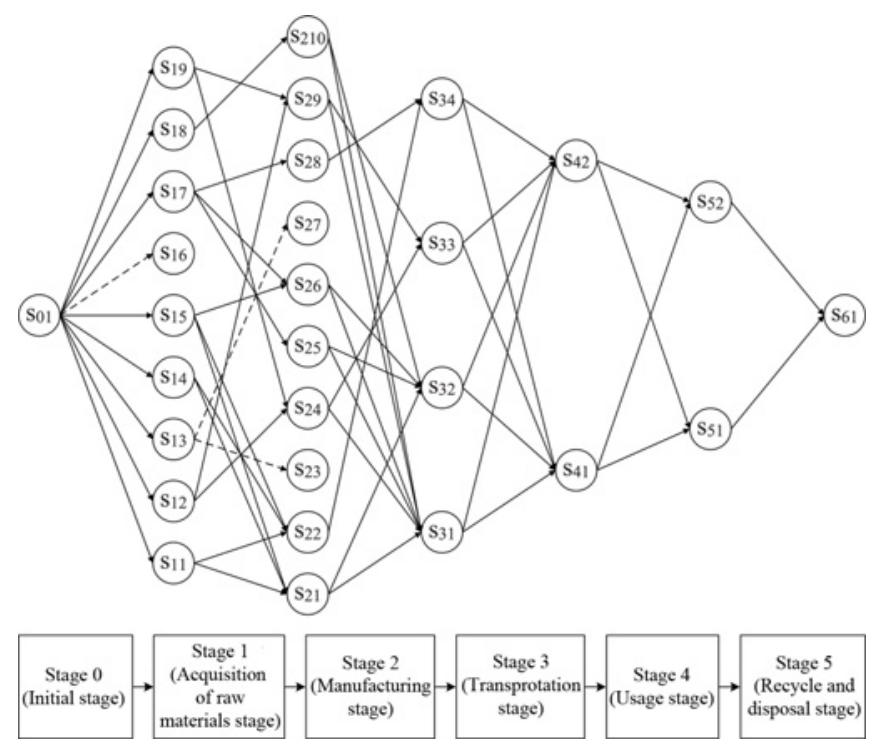

Fig. 2 Dynamic programming model-based low-carbon design for cold heading machine as follows, as the real lines connecting one design state to the next one express the available selections as the control law of each stage in Fig. 2. The step carbon footprints of all decision stages are given by:

$$
\begin{aligned}
& v_{5}\left(x_{5}, u_{5}\right)=f_{5}\left(x_{5}, u_{5}\right)+v_{4}\left[T_{5}\left(x_{4}, u_{4}\right)\right] ; \\
& v_{4}\left(x_{4}, u_{4}\right)=f_{4}\left(x_{4}, u_{4}\right)+v_{3}\left[T_{4}\left(x_{2}, u_{2}\right)\right] ; \\
& v_{3}\left(x_{3}, u_{3}\right)=f_{3}\left(x_{3}, u_{3}\right)+v_{2}\left[T_{3}\left(x_{2}, u_{2}\right)\right] ; \\
& v_{2}\left(x_{2}, u_{2}\right)=f_{2}\left(x_{2}, u_{2}\right)+v_{1}\left[T_{2}\left(x_{1}, u_{1}\right)\right] ; \\
& v_{1}\left(x_{1}, u_{1}\right)=f_{1}\left(x_{1}, u_{1}\right)+v_{0}\left[T_{1}\left(x_{0}, u_{0}\right)\right] ; \\
& v_{0}\left(x_{0}, u_{0}\right)=0 .
\end{aligned}
$$

Furthermore, it is calculated as carbon footprints (Unit: $\mathrm{kg}$ ) from the $s_{i j}$ to $s_{p q}$ related to all possible control laws at each decision stage, through

Table 1 Carbon footprint (CF) from design state $s_{i j}$ to design state $s_{p q}$

\begin{tabular}{cccccccccccc}
\hline$s_{i j}$ & $s_{p q}$ & $\mathrm{CF}$ & $s_{i j}$ & $s_{p q}$ & $\mathrm{CF}$ & $s_{i j}$ & $s_{p q}$ & $\mathrm{CF}$ & $s_{i j}$ & $s_{p q}$ & $\mathrm{CF}$ \\
\hline$s_{01}$ & $s_{11}$ & 0 & $s_{13}$ & $s_{27}$ & 9,132 & $s_{22}$ & $s_{34}$ & 7,776 & $s_{31}$ & $s_{42}$ & 810 \\
\hline$s_{01}$ & $s_{12}$ & 0 & $s_{14}$ & $s_{21}$ & 9,600 & $s_{24}$ & $s_{31}$ & 6,075 & $s_{32}$ & $s_{41}$ & 308 \\
\hline$s_{01}$ & $s_{13}$ & 0 & $s_{14}$ & $s_{22}$ & 9,600 & $s_{24}$ & $s_{33}$ & 6,075 & $s_{32}$ & $s_{42}$ & 308 \\
\hline$s_{01}$ & $s_{14}$ & 0 & $s_{15}$ & $s_{21}$ & 9,500 & $s_{25}$ & $s_{31}$ & 8,100 & $s_{33}$ & $s_{41}$ & 368 \\
\hline$s_{01}$ & $s_{15}$ & 0 & $s_{15}$ & $s_{22}$ & 9,500 & $s_{25}$ & $s_{32}$ & 8,100 & $s_{33}$ & $s_{42}$ & 368 \\
\hline$s_{01}$ & $s_{16}$ & 0 & $s_{17}$ & $s_{25}$ & 9,650 & $s_{26}$ & $s_{31}$ & 7,290 & $s_{34}$ & $s_{41}$ & 2,682 \\
\hline$s_{01}$ & $s_{17}$ & 0 & $s_{17}$ & $s_{26}$ & 9,650 & $s_{26}$ & $s_{32}$ & 7,290 & $s_{34}$ & $s_{42}$ & 2,682 \\
\hline$s_{01}$ & $s_{18}$ & 0 & $s_{17}$ & $s_{28}$ & 9,650 & $s_{28}$ & $s_{34}$ & 7,776 & $s_{41}$ & $s_{51}$ & 650,778 \\
\hline$s_{01}$ & $s_{19}$ & 0 & $s_{18}$ & $s_{210}$ & 9,463 & $s_{29}$ & $s_{31}$ & 5,670 & $s_{41}$ & $s_{52}$ & 650,196 \\
\hline$s_{11}$ & $s_{21}$ & 9,550 & $s_{19}$ & $s_{24}$ & 8,846 & $s_{29}$ & $s_{33}$ & 5,670 & $s_{42}$ & $s_{51}$ & 507,165 \\
\hline$s_{11}$ & $s_{22}$ & 9,550 & $s_{19}$ & $s_{29}$ & 8,846 & $s_{210}$ & $s_{31}$ & 6,885 & $s_{42}$ & $s_{52}$ & 506,583 \\
\hline$s_{12}$ & $s_{24}$ & 8,618 & $s_{21}$ & $s_{31}$ & 7,290 & $s_{210}$ & $s_{32}$ & 6,885 & $s_{51}$ & $s_{61}$ & 4,392 \\
\hline$s_{12}$ & $s_{29}$ & 8,618 & $s_{21}$ & $s_{32}$ & 7,290 & $s_{31}$ & $s_{41}$ & 810 & $s_{52}$ & $s_{61}$ & 4,683 \\
\hline$s_{13}$ & $s_{23}$ & 9,132 & & & & & & & & & \\
\hline
\end{tabular}

Table 2 The design results of cold heading machine

\begin{tabular}{cl}
\hline Nodes & \multicolumn{1}{c}{ Descriptions of design states } \\
\hline$s_{12}$ & Machine body (Resin concrete), Sliding table (Metal, plastic \\
& composite materials), Crankshaft (45CrMo), Transmission gear \\
and transmission spur gear (POM), Flywheel (HT250), etc.
\end{tabular}


the model proposed in Section 2, listed in Table 1.

The above carbon footprints in Table 1 are caculated using the equations from Equ. 2 to Equ. 6. The caculation of carbon footprint from $s_{11}$ to $s_{21}$ is taken as an example to illustrate. The raw material mainly includes $440 \mathrm{~kg}$ steel, $7 \mathrm{~kg}$ aluminum and $6505 \mathrm{~kg}$ cast iron, and their emission factors are obtained from IPCC ${ }^{1}$ as $1.72 \mathrm{~kg} \mathrm{CO}_{2} / \mathrm{kg}, 1.7 \mathrm{~kg}$ $\mathrm{CO}_{2} / \mathrm{kg}$, and $1.35 \mathrm{~kg} \mathrm{CO} / \mathrm{kg}$. And the direct carbon footprint is ignored as it is small. Thus, the carbon footprint from $s_{11}$ to $s_{21}$ is caculated as $440 * 1.72+7 * 1.7+6,505 * 1.35=9,550.45 \approx 9,550 \mathrm{~kg} \mathrm{CO}_{2 \mathrm{e}}$. In this way, all the carbon footprints can be caculated.

\subsection{Results of Low-Carbon Design for Cold Heading Machine}

Eventually, on the basis of the step carbon footprint in each stage obtained above, the objective function could be optimized by Eq. (15). The result is $\mathrm{M}=0+8,618+5,670+368+506,583+4,683=525,922 \mathrm{~kg} \quad \mathrm{CO}_{2 \mathrm{e}}$, with the least carbon footprint path $s_{01} \rightarrow s_{12} \rightarrow \mathrm{S}_{29} \rightarrow \mathrm{S}_{33} \rightarrow \mathrm{S}_{42} \rightarrow \mathrm{S}_{52} \rightarrow \mathrm{S}_{61}$. The corresponding solutions are taken as the lowest-carbon design solutions for cold heading machine, with the approximate number of carbon footprint $526,000 \mathrm{~kg} \mathrm{CO}_{2 \mathrm{e}}$, the design results are shown in Table 2.

There are also several challenges of the proposed approach, as follows: it must collect many data from the industry, it also need some simplification and assumption.

\section{Conclusions}

Low-carbon design plays a significant role in reducing GHGs emissions for the environmental impact on the life cycle of products. This paper is devoted to a dynamic programming-based approach to product low-carbon design for product life cycle. After the product low-carbon design is characterized by a multi-stage decision process in the product life cycle, a dynamic programming method is used to optimize the total carbon footprint of each stage while considering interaction effects of solutions at each stage in product life cycle. The low-carbon design of cold heading machine is given as an example, which demonstrates that the methodology is helpful to reduce product carbon footprint in product life cycle.

\section{ACKNOWLEDGEMENT}

This work is supported by National Natural Science Foundation of China (No. 51305249), National Science and Technology Major Project of China (No. 2013ZX04002081).

\section{REFERENCES}

1. Intergovernmental Panel on Climate Change, "Climate Change 2007-Mitigation of Climate Change: Working Group III Contribution to the Fourth Assessment Report of the IPCC," Cambridge University Press, pp. 447-496, 2007.

2. Yun, J.-H., Jeong, M.-S., Lee, S.-K., Jeon, J.-W., Park, J.-Y., et al., "Sustainable Production of Helical Pinion Gears: Environmental
Effects and Product Quality,” Int. J. Precis. Eng. Manuf.-Green Tech., Vol. 1, No. 1, pp. 37-41, 2014.

3. Wiedmann, T. and Minx, J., "A Definition of Carbon Footprint," ISA Research \& Consulting UK, 2007.

4. British Standards Institution, "Guide to PAS 2050, How to Assess the Carbon Footprint of Goods and Services," 2008.

5. Finkbeiner, M., "Carbon Footprinting-Opportunities and Threats," The International Journal of Life Cycle Assessment, Vol. 14, No. 2, pp. 91-94, 2009.

6. Ramani, K., Ramanujan, D., Bernstein, W. Z., Zhao, F., Sutherland, J., et al., "Integrated Sustainable Life Cycle Design: A Review," Journal of Mechanical Design, Vol. 132, No. 9, Paper No. 091004, 2010.

7. Reap, J., Roman, F., Duncan, S., and Bras, B., "A Survey of Unresolved Problems in Life Cycle Assessment," The International Journal of Life Cycle Assessment, Vol. 13, No. 5, pp. 374-388, 2008.

8. He, B., Deng, Z., Huang, S., and Wang, J., "Application of Unascertained Number for the Integration of Carbon Footprint in Conceptual Design," Proc. of the Institution of Mechanical Engineers, Part B: Journal of Engineering Manufacture, Paper No. 0954405414539495, 2014.

9. Song, J.-S. and Lee, K.-M., "Development of a Low-Carbon Product Design System based on Embedded GHG Emissions," Resources, Conservation and Recycling, Vol. 54, No. 9, pp. 547-556, 2010.

10. Lee, K.-H., "Integrating Carbon Footprint into Supply Chain Management: The Case of Hyundai Motor Company (HMC) in the Automobile Industry," Journal of Cleaner Production, Vol. 19, No. 11, pp. 1216-1223, 2011.

11. Su, J. C., Chu, C.-H., and Wang, Y.-T., “A Decision Support System to Estimate the Carbon Emission and Cost of Product Designs," Int. J. Precis. Eng. Manuf., Vol. 13, No. 7, pp. 1037-1045, 2012.

12. Kuo, T. C., "The Construction of a Collaborative Framework in Support of Low Carbon Product Design," Robotics and ComputerIntegrated Manufacturing, Vol. 29, No. 4, pp. 174-183, 2013.

13. Vadenbo, C., Hellweg, S., and Guillén-Gosálbez, G., "MultiObjective Optimization of Waste and Resource Management in Industrial Networks-Part I: Model Description," Resources, Conservation and Recycling, Vol. 89, pp. 52-63, 2014.

14. Sobrino, F. H., Monroy, C. R., and Pérez, J. L. H., "Biofuels and Fossil Fuels: Life Cycle Analysis (LCA) Optimisation through Productive Resources Maximisation," Renewable and Sustainable Energy Reviews, Vol. 15, No. 6, pp. 2621-2628, 2011.

15. Bellman, R., "Dynamic Programming," Princeton University Press, 1957.

16. Bradley, S., Hax, A., and Magnanti, T., "Applied Mathematical Programming," Addison-Wesley, 1977.

17. He, B. and Wang, J., "Report on Cold Heading Machine," Shanghai University, 2014. 